\title{
Oral vitamin $C$ administration Decreases Training Efficiency and Muscle Mitochondrial Biogenesis in Rats
}

\author{
*Saad M. El-Sekelly, **Mohamed A. Hasan and \\ ***Ibrahem S. Abd Allah \\ * Biochemistry Dept. Faculty of Medicine, Minia University; \\ **Theoretical and Application Group sports Dept. Faculty of Sport \\ Education, Zagazig University and \\ ***Physiology Dept. Faculty of Medicine, Minia University
}

\begin{abstract}
Exercise practitioners often take vitamin $C$ supplements because intense muscular contractile activity can result in oxidative stress, as indicated by altered muscle and blood glutathione concentrations and increases in protein, DNA, and lipid peroxidation. There is, however, considerable debate regarding the beneficial health effects of vitamin $C$ supplementation. The present study was designed to study the effect of vitamin $C$ on training efficiency in rats. Thirty male Albino rats were exercised under protocol for 6 weeks. Ten of the rats were treated with a daily dose of $500 \mathrm{mg} / \mathrm{kg}$ body weight of vitamin $C(0.24 \mathrm{mg} / \mathrm{cm} 2$ body surface area). The administration of vitamin $C$ hampered endurance capacity. The adverse effects of vitamin $C$ may result from its capacity to reduce the exercise-induced expression of key transcription factors involved in mitochondrial biogenesis. These factors are nuclear respiratory factor 1and mitochondrial transcription factor A. Vitamin C also prevented the exercise-induced expression of the antioxidant enzymes superoxide dismutase and glutathione peroxidase. The study showed that Vitamin C supplementation decreases training efficiency because it prevents some cellular adaptations to exercise.
\end{abstract}

\section{INTRODUCTION}

Acute physical exercise induces augmented generation of reactive oxygen species (ROS) in muscle and in other organs ${ }^{(1-3)}$. It has been generally accepted over the past 20 years that increasing the concentrations of antioxidants within a muscle cell should provide greater protection against these oxidizing agents and should reduce fatigue $e^{(4-7)}$. However, the functional significance of exercise-induced oxidative stress is open to discussion. Results from several laboratories indicate that ROS are signals that serve to up-regulate the expression of a number of genes $^{(\mathbf{8 , 9 )}}$.Thus, ROS can exert favorable effects and could be involved in the process of training adaptation. Up-regulation of endogenous antioxidant systems in response to regular training exerts beneficial effects in the prevention of chronic disease processes ${ }^{(\mathbf{1 0})}$ and has also been related to longevity in flies $^{(11)}$ and mice ${ }^{(12)}$.

The maximal capacity to take up, transport and utilize oxygen during 
exercise is $\mathrm{VO}_{2} \max ^{(13)}$. Endurance is defined as the time limit of a person's or animal's ability to maintain a specific power level during a running protocol $^{(\mathbf{1 4 )}}$. Large-scale epidemiologic studies of humans with and without cardiovascular disease show that low aerobic exercise capacity is a stronger predictor of mortality than are other established risk factors, such as diabetes, smoking, hypertension, or chronic obstructive pulmonary disease ${ }^{(15,16,17,18)}$. These observations are consistent with the role of impaired regulation of mitochondrial function as an important mechanism for low aerobic capacity ${ }^{(\mathbf{1 9})}$. The relations among $\mathrm{VO}_{2} \max$, muscle oxidative capacity, endurance capacity, and maximal aerobic workload capacity have been discussed for years ${ }^{(20)}$. Davies et al. (21) concluded that muscle oxidative capacity (i.e. the mitochondrial content of muscle) was a major determinant of endurance capacity, whereas $\mathrm{VO}_{2}$ max was only indirectly related to endurance capacity but was directly related to exercise intensity. In eukaryotic cells, mitochondrial biogenesis requires gene products from 2 physically separated genomes: one contained within the organelle and the other contained within the nucleus. Peroxisome proliferatoractivated receptor co-activator 1 (PGC-1) is a recently identified coactivator of nuclear receptors. It powerfully induces mRNA expression for important nuclear transcription factors such as nuclear respiratory factor 1 (NRF-1) and mitochondrial transcription 1 factor A (mTFA) ${ }^{\text {(22) }}$.
The aim of the present study was to explore the effects of vitamin $\mathrm{C}$ administration on training-induced increases in $\mathrm{VO}_{2} \max$ and endurance capacity and on the skeletal muscle mitochondrial biogenesis in rats.

\section{SUBJECTS \& METHODS}

\section{Animals:}

Thirty healthy adult male Albino rats weighing 180-220 grams obtained from the animal house of Faculty of Science, Minia University. They were kept in galvanized iron cages under standardized conditions to achieve acclimatization. All animals were fed a rodent maintenance diet and given free water ad-libitum. They were randomly divided into 3 equal groups.

Group 1: untrained (10 rats). Group 2: trained (10 rats). Group 3: trained with vitamin $\mathrm{C}$ supplementation (10 rats).

The rats in the study were trained for 6 weeks. The study was performed in accordance with the guidelines for the care and use of laboratory animal (23).

\section{Supplementation of rats with vitamin $\mathbf{C}$ :}

Vitamin $\mathrm{C}$ was administered orally to rats. The dose administered to rats was $500 \mathrm{mg} / \mathrm{kg}$ body wt, which is equivalent to $0.24 \mathrm{mg} / \mathrm{cm} 2$ body surface area (24). That dose is 4-fold that in humans. That high dose of vitamin $\mathrm{C}$ was given to the animals because it has proved to be very effective as an antioxidant in previous studies ${ }^{(4,25)}$.

\section{Exercise protocol:}

Endurance-trained animals were exercised $5 \mathrm{~d} /$ week on an animal treadmill (Model 1050 LS Exer3/6; 
Columbus Instruments, Columbus, $\mathrm{OH})$ at $75 \% \mathrm{VO}_{2} \max$. A modification of the protocol of Davies et al., ${ }^{(21)}$ was followed The first day's training session was 25 minutes long. The duration of each work period was increased by 5 minute/day until, on the last day of $3^{\text {rd }}$ week, rats were required to run for a full 85 minutes. The group of animals trained for 6 weeks were maintained at 85 minutes exercise/day for the final 6 weeks of the study with only a modification of the running speed $(30 \mathrm{~m} /$ minutes at a grade of $15 \%$ ). The untrained group was exercised at the same speed for only 10 minutes every 3 days for the entire 6-weeks period. Exercise motivation was provided for all rats by means of an electronic shock grid at the treadmill rear. Twenty-four hours after the last training session, an endurance test was administered to each rat. Exercise endurance capacity was assessed during a run to exhaustion at $26.8 \mathrm{~m} /$ minutes at a grade of $15 \%$. As each endurance test progressed, animals experienced increasing difficulty in matching the pace of the treadmill. The endpoint for every test was marked by a rat's inability to return to the treadmill belt from the shock grid and by the rat's incapacity to right itself when placed supine on a flat surface. The time to exhaustion was recorded for each rat. All of the animals were also given a graded intensity treadmill test to determine $\mathrm{VO}_{2} \mathrm{max}$. After an initial 2 minutes at $15 \%$ grade and 26.8 $\mathrm{m} /$ minutes, treadmill speed was increased by $6.7 \mathrm{~m} / \mathrm{min}$ every 2 minutes until the animal failed to maintain the intensity of the exercise. The maximal running speed was considered the maximal aerobic workload capacity of the animal ${ }^{(20)}$. After the tests, animals were given 48 hours of complete rest before being killed for skeletal muscle recovery and analysis. During these 2 days, the animals were still supplemented with the same dose of vitamin C. Rats were anesthetized with $50 \mathrm{mg}$ sodium pentobarbital $/ \mathrm{kg}$ by intraperitoneal injection. Sufficient blood samples for biochemical analysis were taken from the venous plexus localized in the orbit behind the eye ball using capillary pipette. Rats were killed by an overdose of the anesthetic. The soleus and gastrocnemius muscles were obtained by quick removal. The muscles were freeze-clamped immediately and stored at $-80^{\circ} \mathrm{C}$ until used.

\section{RT-polymerase chain reaction:}

RNA was isolated from rat muscles by using Trizol RNA extraction (Life Technologies, Rockville. Md). Reverse transcriptase and the first PCR were combined and the second PCR was done using the following specific primers which are CGTGCTCCCACACATCAATC and TGAACGTCACCGAGGAGAAG for manganese superoxide dismutase (Mn-SOD);

GACATCAGGAGAATGGC and CATCACCAAGCC AATACCAG for glutathione peroxidase (GPx); GTATGCTAAGTGCTGATGAA and GG GTTTGGAGGGTGAGAT for NRF-1 and AGTTCATACCTTCGATTTTC and TGACTTG AGTTAG CTGC for mTFA yielding products under the following conditions: one cycle of 5 min at $94^{\circ} \mathrm{C}, 30$ cycles of $30 \mathrm{~s}$ at $94^{\circ} \mathrm{C}$ and $40 \mathrm{~s}$ at $72{ }^{\circ} \mathrm{C}$ and final extension 
of $7 \mathrm{~min}$ at $72^{\circ} \mathrm{C}$ using DNA thermal cycler 480 (Perkin Elmer, Cetus)for 30 minutes.

Gel electrophoresis detection: five micro liters buffer was added to $20 \mu 1$ of the PCR product. The amplified gene was analyzed by electrophoresis in $1.2 \%$ agarose gel using standard method. The Ethidium bromide stained gel was examined under ultraviolet light. The size of the bands was assessed by direct comparison with standard molecular weight markers ${ }^{\text {(26). }}$.

Statistical Analysis:

Results were expressed as mean \pm standard deviation (S.D.). Students's ttest was used. $\mathrm{P}$ value of less than 0.05 was considered significant.

\section{RESULTS}

Vitamin C administration
significantly hampers endurance
capacity and does not improve

$\mathrm{VO}_{2} \mathrm{max}$ associated with training in rats:

Training significantly $(P<0.004)$ increased the maximal running time in rats (Table 1), from $98.3 \pm 6.1$ minutes in untrained rats to $279.3 \pm 14.4$ minutes in trained rats. However, that increase was significantly $(P<0.004)$ prevented by daily supplementation with vitamin $C$. In the supplemented animals, the running time increased only $15.5 \%$, from $103.1 \pm 5.4$ minutes to $118.6 \pm 10.1$ minutes. Although we found a dramatic effect of vitamin $\mathrm{C}$ on endurance time in animals, we did not find the same effect on $\mathrm{VO}_{2} \mathrm{max}$. We performed a $\mathrm{VO}_{2} \max$ test before and after the training period ( 6 weeks) and found a significant $(P<0.005)$ increase in $\mathrm{VO}_{2} \max$ of $33.6 \%$ after 6 weeks of training in the unsupplemented and an increase in $\mathrm{VO}_{2} \mathrm{max}$ of $3 \%$ in the supplemented group.

Table (1): $\quad$ Training-induced increases in maximum oxygen uptake in $\mathrm{VO}_{2}$ max and maximal endurance time in rats and the effect of vitamin $\mathrm{C}$ administration

\begin{tabular}{|c|l|l|l|}
\hline & $\begin{array}{l}\text { Before training } \\
(\mathbf{n}=\mathbf{1 0})\end{array}$ & $\begin{array}{l}\text { After training } \\
(\mathbf{n}=\mathbf{1 0})\end{array}$ & $\begin{array}{l}\text { Relative } \\
\text { difference }\end{array}$ \\
\hline $\mathrm{VO}_{2}$ max. & & & \\
\hline Control (untrained) & $49.3 \pm 1.6$ & - & \\
\hline No supplementation & $55.3 \pm 3.1$ & $88.9 \pm 6.1^{* *}$ & 33.6 \\
\hline Vitamin C supplementation & $56.3 \pm 2.2$ & $59.3 \pm 1.6$ & 3 \\
\hline Endurance capacity & & & \\
\hline Control (untrained) & $49.3 \pm 1.6$ & - & \\
\hline No supplementation & $98.2 \pm 6.1$ & $279.4 \pm 14.4^{*}$ & 181.2 \\
\hline Vitamin C supplementation & $103.1 \pm 5.4$ & $118.6 \pm 10.1^{*}$ & 15.5 \\
\hline$P<0.004$ P $<0.005$ & & & \\
\hline
\end{tabular}

* $P<0.004$ ** $P<0.005$ 
ROS formed in exercise activated the expression of antioxidant enzymes in skeletal muscle, but vitamin $C$ administration prevents the activation:

The group of animals trained for 6 weeks had higher mRNA concentrations of 2 antioxidant enzymes, Mn-SOD and GPx, in their skeletal muscle after the training. However, that increase was prevented by supplementation with vitamin $\mathrm{C}$, as shown in Figure 1. Thus, supplementation with an antioxidant vitamin hinders the adaptation of these enzymes to training.

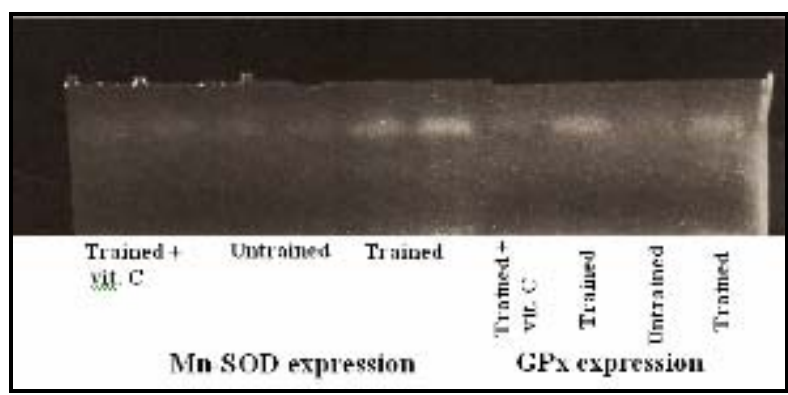

Fig. (1): Expression of manganese-superoxide dismutase (Mn-SOD) and glutathione peroxidase (GPx), measured by real-time reverse transcriptase-polymerase chain reaction in skeletal muscle samples of untrained rats, rats trained for 6 weeks and rats trained for 6 weeks but treated with vitamin $\mathrm{C}$.

ROS formed in exercise activated mitochondrial biogenesis in skeletal muscle, but vitamin $\mathrm{C}$ administration prevents the activation:

The group of animals trained for 6 weeks had higher skeletal muscle
mRNA concentrations of NRF-1 and mTFA which were followed by changes in the protein concentrations of these nuclear transcription factors. Supplementation with vitamin C prevented all of these effects (Figure 2).

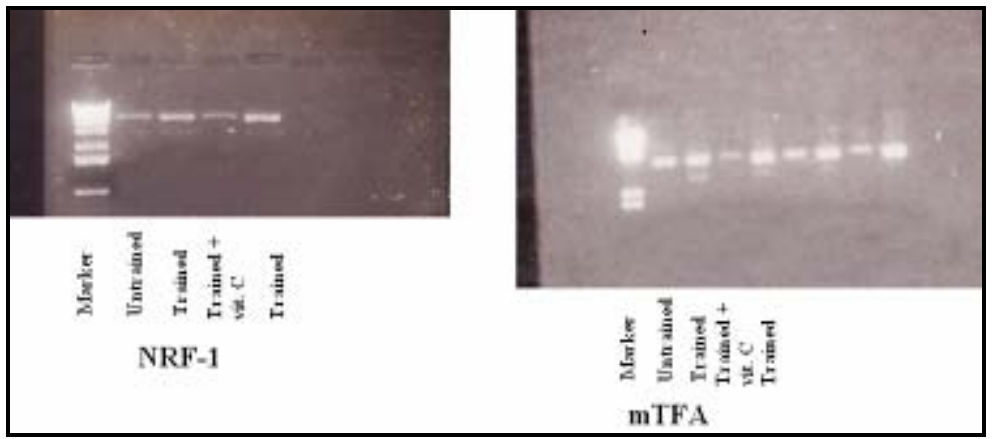

Fig. (2): Training-induced up-regulation of nuclear respiratory factor 1 (NRF-1) and mitochondrial transcription factor A (mTFA) is prevented by vitamin $\mathrm{C}$ administration. 


\section{DISCUSSION}

The maximal rate of oxygen consumption $\left(\mathrm{VO}_{2} \max \right)$ increased significantly after 8 weeks of training in both the non-supplemented men and the men supplemented with vitamin $C^{(20)}$. Nielsen et al. ${ }^{(27)}$ found no effect of antioxidant supplementation on $\mathrm{VO}_{2} \max$ in athletes, a similar result was found in our animal study. A significant increase in $\mathrm{VO}_{2}$ max after 6 weeks of training in both the non-supplemented (33.6\% increase) and the vitamin $\mathrm{C}$ supplemented (3\% increase) groups was found. Endurance capacity is dependent mainly on the mitochondrial content of skeletal muscle (muscle oxidative capacity), not on the cardiovascular factors previously mentioned (20) . Thus, to determine the effect of the antioxidant administration and exercise in the mitochondrial muscle content, we performed another series of experiments in rats. Six weeks of training is approximately the period required to achieve a new steady state mitochondrial content in response to endurance training (15), although changes in mitochondrial protein and mRNA content can be apparent at much earlier time points ${ }^{(22)}$. In the current study, endurance-trained rats showed a clear increase in their endurance capacity. However, the administration of vitamin $\mathrm{C}$ dramatically decreased that adaptation. Such finding is in agreement with a previous study in which it was shown, using endurancetrained rats, that $\mathrm{VO}_{2} \max$ increased only $14 \%$ despite a $100 \%$ increase in muscle oxidative capacity ${ }^{(21)}$. One of the main conclusions from that study was that the mitochondrial content of muscle is a major determinant of endurance capacity, whereas the maximal aerobic workload capacity appears to be regulated by $\mathrm{VO}_{2} \max ^{(21)}$. We offer a molecular explanation for that result (i.e. that vitamin $\mathrm{C}$ decreases exercise-induced mitochondrial biogenesis and the antioxidant capacity in skeletal muscle). We have found that exercise training up-regulates the following mitochondrial pathway: NRF-1 and mTFA. All of these adaptations are prevented by vitamin C administration. When supplementing with vitamin $\mathrm{C}$, there is the possibility that it may act as a pro-oxidant in vivo. These pro-oxidative reactions of vitamin $\mathrm{C}$ readily occur in vitro, and it has been shown that they also may have relevance in vivo ${ }^{(28)}$. A high intake of iron along with ascorbic acid could increase in vivo lipid peroxidation of LDL and therefore, could increase the risk of atherosclerosis ${ }^{(29)}$. However, another study showed that, in iron overloaded plasma, ascorbic acid acts as an antioxidant and prevents oxidative damage to lipids in vivo ${ }^{(30)}$.

It is important to consider that free radicals are not always damaging to cells; in many cases, they serve as signals to adapt muscle cells to exercise via modulation of gene expression $^{(\mathbf{9}, 31)}$. We have found that training causes an increase in 2 major antioxidant enzymes (Mn-SOD and GPx) in skeletal muscle. We were surprised to see that vitamin $\mathrm{C}$ prevents these beneficial effects of training. On the basis of the paradigm that enzymatic antioxidant systems 
such as Mn-SOD and GPx provide a first line defense against ROS, it is expected that exercise may induce these protective mechanisms. Moderate exercise increases life span and decreases disability in rats ${ }^{(\mathbf{1 2})}$ and humans $^{(\mathbf{1 5})}$. We report here that exercise training causes an increase in the expression of antioxidant enzymes, which is prevented by the administration of vitamin $\mathrm{C}$.

A major conclusion that can be drawn from our experiment is that exercise itself is an antioxidant, because training increases the expression of 2 antioxidant enzymes related with longevity-namely, SOD and GPx. We provide evidence that the continuous presence of small stimuli, such as low concentrations of ROS, in fact induces the expression of antioxidant enzymes as a defense mechanism. Low concentrations of radicals may be considered to be beneficial, because they act as signals to enhance defenses, rather than being deleterious, as they can be when they are at higher concentrations. It is known that exercise can modify the rates of several of steps, leading to mitochondrial biogenesis. An understanding of how exercise can produce that effect could help us decide whether exercise is beneficial for patients suffering from mitochondrial disorders, as well as a variety of metabolic diseases ${ }^{(32)}$.

The second major conclusion that can be drawn from our experiment is that supplementation with vitamin $\mathrm{C}$ lowers training efficiency. Endurance capacity is directly related to the mitochondrial content. That variable is seriously hampered by antioxidant supplementation, whereas $\mathrm{VO}_{2} \mathrm{max}$, which is dependent also on the cardiovascular system adaptations, is not significantly affected. Such information is helpful for nutritionists who must prepare diets for athletes whose performance is dependent on their endurance capacity. It should be taken into account that some of the world's best marathon runners exhibit rather modest measures of $\mathrm{VO}_{2} \max { }^{(33)}$. Antioxidant supplementation is very popular among athletes, but data showing any beneficial effects on muscle function of that type of widespread practice are elusive. In fact, several reports have shown deleterious effects of antioxidant treatment. As early as 1971, it was shown that vitamin E supplementation $(400 \mathrm{IU} / \mathrm{d}$ for 6 weeks) caused unfavorable effects on endurance performance ${ }^{(34)}$. In 1996 and 1997, a Scandinavian journal published 2 reports showing the deleterious effects of ubiquinone- 10 supplementation on the performance of humans after a high-intensity training program ${ }^{(35,36)}$. Coombes et al. ${ }^{(37)}$ reported that, in the muscles of un-fatigued rats, supplementation with vitamin $\mathrm{E}$ and lipoic acid depressed muscle tetanic force at low stimulation frequencies. One year later, it was shown that supplementation of racing greyhounds with one $\mathrm{g}$ vitamin $\mathrm{C} /$ day for 4 weeks significantly lowered their speed ${ }^{(38)}$. Intense exercise increased lipid peroxidation, decreased Bcl-2 expression and induced an antioxidant response in lymphocytes. Supplementation with moderate levels of antioxidant vitamins reduced exercise-induced oxidative damage, but without blocking the cellular 
adaptation to exercise ${ }^{(39)}$. Exerciseinduced oxidative stress ameliorates insulin resistance and causes an adaptive response promoting endogenous antioxidant defense capacity. Supplementation with antioxidants may preclude these health-promoting effects of exercise in human ${ }^{(40)}$. Taking into account that a high fitness level is associated with a lower risk of premature death from any cause, the effect of vitamin $\mathrm{C}$ administration on endurance capacity has important implication for nutritionists, physicians, exercise trainers and practitioners. Thus, the common practice of taking vitamin $\mathrm{C}$ supplements during training (for both health-related and performancerelated physical fitness) should be seriously questioned. The results of the present study show that supplementation with vitamin $\mathrm{C}$ does not improve but partially decreases the improvement in $\mathrm{VO}_{2} \max$ associated with exercise training in rats. Moreover, it very significantly hampers endurance capacity in animal as a result of the decrease in mitochondriogenesis that is normally associated with exercise training.

\section{REFERENCES}

1. Davies K.J., Quintanilha A.T., Brooks G.and Packer L. (1982): Free radicals and tissue damage produced by exercise. Biochem. Biophys. Res. Commun., 107:1198 -205.

2. Commoner B., Townsend. J. and Pake G.E.(1954): Free radicals in biological materials. Nature 174:689 -691.
3. Koren A., Schara M.and Sentjurc M. (1980): EPR measurements of free radicals during tetanic contractions of frog skeletal muscle. Period. Biol., 82:399-401.

4. Sastre J., Asensi M.and Gasco E., (1992): Exhaustive physical exercise causes oxidation of glutathione status in blood: prevention by antioxidant administration. Am. J. Physiol., 263:R992-995.

5. Jackson M.J.(1987): Muscle damage during exercise: possible role of free radicals and protective effect of vitamin E. Proc. Nutr. Soc., 46:77-80.

6. Konig D., Wagner K.H., Elmadfa I. and Berg A. (2001): Exercise and oxidative stress : significance of antioxidants with reference to inflammatory, muscular, and systemic stress. Exerc. Immunol. Rev., 7:108 133.

7. 7- Hathcock J.N., Azzi A. Blumberg J.and Jackson M.J.(2005): Vitamins E and Care safe acrossa broad range of intakes. Am. J. Clin. Nutr., 81:736-745.

8. Gomez-Cabrera M.C., Borras C., Pallardo F.V., Sastre J., Ji L.L. and Vina J. (2005): Decreasing xanthine oxidasemediated oxidative stress prevents useful cellular adaptations to exercise in rats. J. Physiol., 567:113-120.

9. Khassaf M., McArdle A.and Esanu C. (2003): Effect of vitamin $\mathrm{C}$ supplements on antioxidant defence and stress proteins in human lymphocytes 
and skeletal muscle. J. Physiol., 549:645-652.

10. Warburton D.E., Nicol C.W. and Bredin S.S.(2006): Health benefits of physical activity: the evidence. CMAJ., 174:801-809.

11. Orr W.C. and Sohal R.S.(1994): Extension of life-span by overexpression of superoxide dismutase and catalase in Drosophila melanogaster. Science 263:1128-1130 .

12. Navarro A., Gomez C., LopezCepero J.M. and Boveris A.(2004) : Beneficial effects of moderate exercise on mice aging : survival, behavior, oxidative stress, and mitochondrial electron transfer. Am. J. Physiol. Regul. Integr. Comp. Physiol., 286: R505-511.

13. Wagner

P.D.(1996):

Determinants of maximal oxygen transport and utilization. Annu. Rev. Physiol.Heart Circ. Physiol., 58:21-50.

14. 14-McArdle W.D., Katch F.I.and Katch V.L.(1996): Exercise physiology: energy, nutrition and human performance. $4^{\text {th }}$ ed. Baltimore, MD; Williams \& Wilkins.

15. Myers J., Prakash M., Froelicher V., Do D., Partington S. and Atwood J.E. (2002): Exercise capacity and mortality among men referred for exercise testing. N. Engl. J. Med., 346:793-801.

16. Yusuf S., Hawken S.and Ounpuu S.(2004): Effect of potentially modifiable risk factors associated with myocardial infarction in 52 countries (the INTERHEART Study) : case- control study. Lancet 364:937952.

17. Kavanagh T., Mertens D.J.and Shephard R.J.(2003): Long-term cardio-respiratory results of exercise training following cardiac transplantation. Am. J. Cardiol., 91:190-194.

18. Kavanagh T., Mertens D.J. and Hamm L.F. (2002): Prediction of long-term prognosis in 12169 men referred for cardiac rehabilitation. Circulation 106:666-671.

19. Wisloff U., Najjar S.M. and Ellingsen O.(2005): Cardiovascular risk factors emerge after artificial selection for low aerobic capacity. Science $307: 418-420$.

20. Davies K.J., Packer L. and Brooks G.A.(1982): Exercise bioenergetics following sprint training. Arch. Biochem. Biophys., 215:260 -265.

21. Davies K.J., Packer L. and Brooks G.A.(1981): Biochemical adaptation of mitochondria, muscle, and whole-animal respiration to endurance training. Arch. Biochem. Biophys., 209:539 -554.

22. Hood D.A.(2001) : Invited review: contractile activityinduced mitochondrial biogenesis in skeletal muscle. J. Appl. Physiol., 90:1137-57.

23. American Veterinary Medical Association (AVMA) (1993) : Report of the AVMA panel on euthanasia. J. Amer. Wet. Med. Assoc., 202(2): 229-249.

24. Lack J.A.and Stuart-Taylor M. E. (1997): Calculation of drug dosage and body surface area of 
children. Br. J. Anaesth., 78:601605.

25. Morh D. and Stocker R. (2002): Selective and sensitive measurement of vitamin $\mathrm{C}$, ubiquinol-10 and other lowmolecular-weight antioxidants. In: Punchard NA, Kelly FJ, eds. Free radicals $-\mathrm{a}$ practical approach. Oxford, United Kingdom: Oxford University Press., 271- 286.

26. Inchauspe $G$, Abe $K$, Zebdee s, Naseff $M$ and Prince A. (1991): Use of conserved sequences from hepatitis $\mathrm{C}$ virus for the detection of viral RNA infected sera by polymerase chain reaction. Hepatology 14: 595-600.

27. Nielsen A.N., Mizuno M. and Ratkevicius A. (1999): No effect of antioxidant supplementation in triathletes on maximal oxygen uptake, 31P-NMRS detected muscle energy metabolism and muscle fatigue. Int. J. Sports Med., 20:154-158.

28. Childs A., Jacobs C., Kaminski T., Halliwell. and Leeuwenburgh C. (2001): Supplementation with vitamin $\mathrm{C}$ and $\mathrm{N}$-acetyl-cysteine increases oxidative stress in humans after an acute muscle injury induced by eccentric exercise. Free Radic. Biol. Med., 31:745-753.

29. Berger T.M., Polidori M.C. and Dabbagh A. (1997): Antioxidant activity of vitamin $\mathrm{C}$ in ironoverloaded human plasma. J. Biol. Chem., 272: 15656-15660.

30. Chen K., Suh J., Carr A.C., Morrow J.D., Zeind J. and Frei B. (2000): Vitamin $C$ suppresses oxidative lipid damage in vivo, even in the presence of iron overload. Am. J. Physiol. Endocrinol. Metab., 279:E1406 1412.

31. Close G.L., Ashton T., Cable T. and Carr A.(2006): Ascorbic acid supplementation does not attenuate post-exercise muscle soreness following muscledamaging exercise but may delay the recovery process. Br. J. Nutr., 95:976-981.

32. Joseph A.M., Pileqaard H., Litvintsev A. and Hood D.A. (2006): Control of gene expression and mitochondrial biogenesis in the muscular adaptation to endurance exercise. Essays Biochem., 42: 13-29.

33. Costill. L., Fink W.J. and Pollock M. L. (1976): Muscle fiber composition and enzyme activities of elite distance runners. Med. Sci. Sports 8:96-100.

34. Sharman I.M., Down M.G. and Sen R.N. (1971) :The effects of vitamin $\mathrm{E}$ and training on physiological function and athletic performance in adolescent swimmers. Br. J. Nutr., 26:265-276.

35. Malm C., Svensson M., Ekblom B. and Sjodin B. (1997): Effects of ubiquinone-10 supplementation and high intensity training on physical performance in humans. Acta Physiol. Scand., 161:379-84.

36. Malm C., Svensson M., Sjoberg B., Ekblom B. and Sjodin B. (1996): Supplementation with ubiquinone-10 causes cellular damage during intense exercise. Acta Physiol. Scand., 157:511512. 
37. Coombes J.S., Powers S.K., Rowell B. and Scott K.C.(2001): Effects of vitamin $\mathrm{E}$ and alphalipoic acid on skeletal muscle contractile properties. J. Appl. Physiol., 90:1424-1430.

38. Marshall R.J., Scott K.C.and Hill R.C. (2002): Supplemental vitamin $C$ appears to slow racing greyhounds. J. Nutr., $132(6$ suppl.2):1616S-1621S.

39. Antoni S., Pedro T.R, Antoni A., Nuria., Isabel L., Josep A. and Tura ${ }^{a}$ A.P.(2008): Influence of an Antioxidant VitaminEnriched Drink on Pre- and PostExercise Lymphocyte Antioxidant System Ann. Nutr. Metab., 52:233-240.

40. Ristow M., Zarse K., Oberbach A., Kloting N., Birrioner M., Kiehntopf M., Sturnvoll M., Kahn C.R. and Bluher $M$. (2009): Antioxidants prevent health- promoting effects of physical exercise in humans. Proc. Natl. Acad. Sci, U.S. A., 26; 106(21): 8665-8670. 


\section{تناول فيتامين ج بالفم يقلل الكفاءة التدريبة والحيوية الجينية الميتوكوندرية

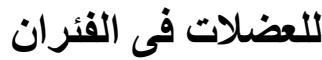

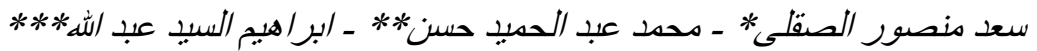

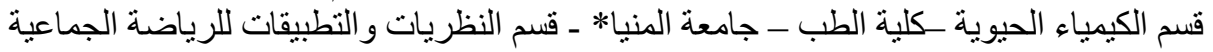

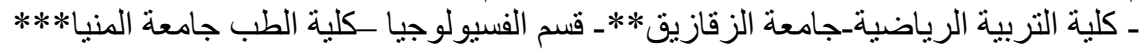

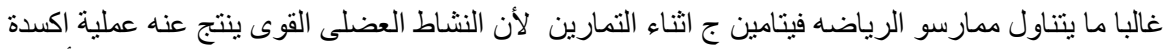

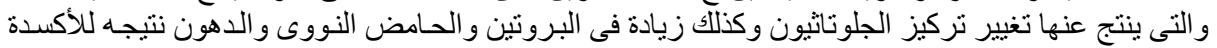

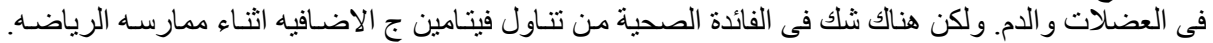

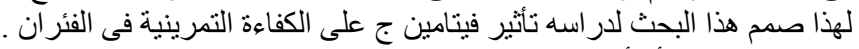

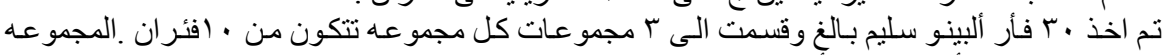

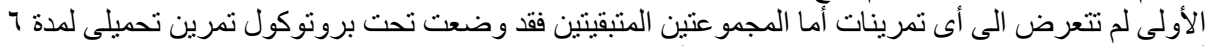

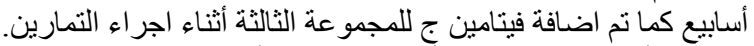

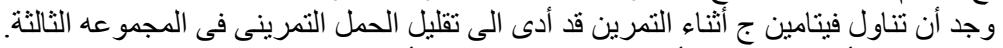

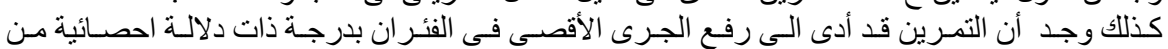

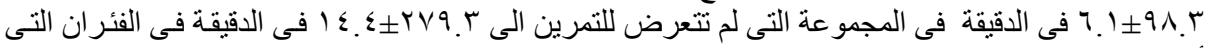
أدت التمارين.

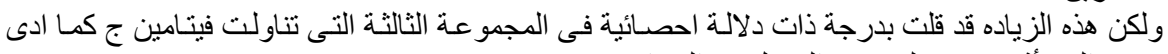

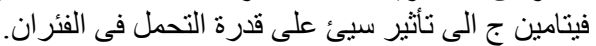

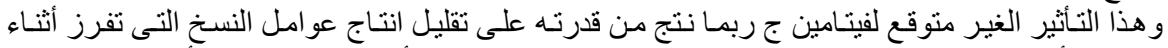

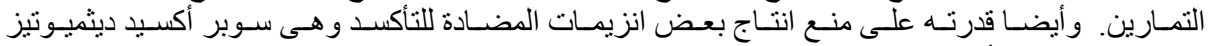

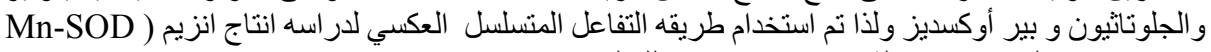

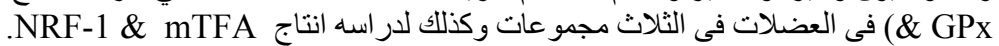

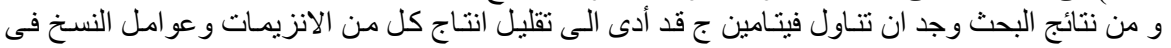
المجمو عة الثالثة. ولذا فان هذه الدراسـة قد أوضحت أن تنـاول فيتامين ج قد أدى الى تقليل الكفاءة التمرينية عن طريق منع بعض التكيفات التى تحدث داخل الخليه اثناء التمرين. 